\title{
Reseña bibliográfica: Moore, D. W. (2020). Polybius. Experience and Lessons of History, Leiden - Boston: Brill, 168 pp.
}

\author{
Palabras clave: Polibio - Historiografía - Didáctica
}

Keywords: Polybius - Historiography - Didactics

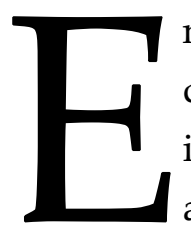

n Polybius. Experience and the Lessons of History, Moore explora los aspectos didácticos, metodológicos e historiográficos de las Historias de Polibio. El interés por investigar algunos de los rasgos menos trabajados del historiador aqueo se ha visto impulsado por trabajos como The Shaping of Narrative in Polybius (Miltsios, 2013), Cultural Politics in Polybius' Histories (Champion, 2004), a nivel nacional por la obra de Moreno Leoni (2017) Entre Roma y el Mundo Griego. Memoria, autorrepresentación y didáctica del poder en las Historias de Polibio, así como por aportes sobre otros historiadores del mundo clásico (el trabajo comparte una aproximación que tiene mucho en común con Livy's Exemplary History de Chaplin, 2001).

En esta obra, el autor se propone examinar la aparente contradicción que existe en las Historias respecto a la posibilidad de que el público del género histórico obtenga experiencias útiles para la vida política a partir de la lectura de su tratado. Es sabido que, según Polibio, solo aquellos que se dedican a los asuntos públicos serían capaces de transmitir las lecciones necesarias para la escritura del género y que la sola adquisición de conocimientos por vía literaria sería insuficiente para la comprensión de los hechos del pasado.

El libro está dividido en seis capítulos. En el primero, el autor analiza el uso de los

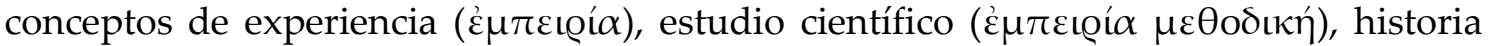
pragmática ( primeros pasajes del libro 1 de las Historias, puesto que es allí donde Polibio introduce muchas de sus ideas centrales acerca de la metodología que va a utilizar a lo largo de la obra. Moore argumenta que, al optar por esta introducción, Polibio toma parte en los debates del período Helenístico acerca del valor de la experiencia como forma de conocimiento, y sostiene que el mismo propone una interpretación alternativa: la Historia como disciplina que permite al lector (el varón dedicado a la política) adquirir la experiencia necesaria para la administración de los asuntos públicos. Moore intenta probar que, en un nivel abstracto, estos conceptos son presentados de forma

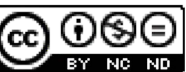


contradictoria a lo largo de estos capítulos iniciales, porque no coinciden con las reflexiones posteriores (particularmente aquellas del capítulo 35 del mismo libro y las del libro 12), y que la tensión entre los mismos no puede resolverse solo a partir de un análisis teórico de estos términos.

Moore sostiene que, si queremos explicar estas aparentes contradicciones, tenemos que estudiar la narración de los hechos históricos, y en particular seguir el desarrollo de los personajes más importantes de la obra para ver cómo estos conceptos son utilizados en relación con ellos. En el capítulo 2, el autor elige analizar en detalle la representación de Aníbal Barca, y estudia las alteraciones que sufre su representación, desde las críticas por su rol en el comienzo de la guerra (en 3.15, donde, según Moore, esto le sirve a Polibio para castigar a aquellos que no hacen una lectura correcta de la causalidad), pasando por su papel como fuente de información histórica modelo (el monumento del promontorio Lacinio), hasta sus discursos a las tropas luego del cruce de los Alpes, en donde, según Polibio, Aníbal utiliza los recursos propios del historiador/estadista para crear ejemplos útiles e inspirar a sus hombres. La maduración de este personaje, con sus éxitos y fracasos, le sirve a Moore para argumentar que, en la carrera de Aníbal, Polibio busca demostrar otro de los puntos centrales de su obra: la mutabilidad de la Fortuna (Túxๆ). Hacia el final de la guerra, Aníbal ya ha aprendido esta dura lección, según el autor, y es por eso que puede poner en su discurso antes de la batalla de Zama (15.6.47.8), palabras que son reminiscentes de este doloroso aprendizaje, las cuales, por otro lado, se ven confirmadas por el resultado de la batalla.

Esta última idea se estudia en mayor extensión en el capítulo 3, en donde Moore argumenta que la carrera de Escipión el Africano puede ser comprendida como un intento por parte de Polibio de probar que solo los estadistas que pueden aprender de los errores ajenos, una habilidad poco frecuente, son capaces de aprovechar efectivamente las lecciones que el género tiene para ofrecerle a los lectores. Es decir, que es la combinación de experiencia personal y conocimiento histórico, la que le permite al Africano aprovechar los recursos del pasado para alcanzar el triunfo. El comportamiento modelo de Escipión es comparado favorablemente con el análisis de otras figuras históricas, entre las que sobresale Filipo V de Macedonia, un personaje que, según Moore, representa la incapacidad para aprender las lecciones del pasado. En cambio, Escipión, no solo despliega todas las habilidades convenientes para un estadista, especialmente racionalidad ( $\lambda$ o $\gamma\llcorner\sigma \mu o ́ s)$, sino que logra predecir los resultados con éxito precisamente por la destreza que demuestra al evitar caer en los mismos errores que sus predecesores sin necesidad de experimentarlos él mismo.

El capítulo 4 está dedicado a responder los interrogantes que no pueden ser resueltos a partir de los capítulos biográficos sobre Aníbal y Escipión. Moore argumenta que, en verdad, las virtudes que encarna el Africano se corresponden con las del cuerpo social romano en su conjunto, y que esta existencia en paralelo puede apreciarse haciendo una lectura cuidadosa del libro 6 de las Historias. Fundamentalmente, estas virtudes pueden verificarse en la habilidad del pueblo romano para aprender de sus propios errores y 
para retener, gracias a sus costumbres y leyes ( que les permitan superar el inevitable ciclo de corrupción de su sistema político

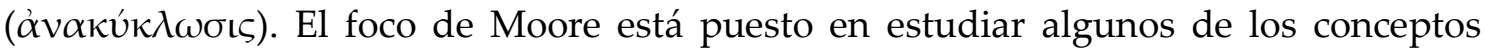
centrales del libro 6, como las formas de gobierno, el mecanismo que explica los cambios en el mismo y la singular habilidad de los romanos para extraer lecciones de su práctica política. El autor pasa luego a analizar el caso de Horacio Cocles, uno de los héroes de la República, así como la práctica del funeral aristocrático, en donde se revela con mayor claridad, según Moore, la habilidad del pueblo romano para conservar el recuerdo de las acciones memorables.

Retomando las conclusiones del capítulo 4, Moore argumenta en el capítulo siguiente que es posible comparar los resultados del análisis del libro 6 con la representación de los romanos a lo largo de la Primera y Segunda Guerra Púnicas: la razón principal por la cual estos serían capaces de vencer a los cartagineses debería entonces buscarse en la habilidad del pueblo quiritario para aprender efectivamente de sus errores (representado en las Historias, según Moore, por las victorias navales y por su predisposición a realizar importantes esfuerzos colectivos), así como por su capacidad para sacar rédito de estos aprendizajes y retenerlos en la memoria comunitaria de manera permanente. En contraposición, Moore argumenta que los cartagineses, a pesar de contar con líderes de excepcional habilidad, como Aníbal y su padre, Amílcar, son incapaces de sacar provecho de los desastres, y en términos generales, no pueden aprender de los errores al mismo paso que los romanos.

En el capítulo final, el autor analiza las carreras de Emilio Paulo y Escipión Emiliano, este último amigo personal de Polibio. Según Moore, lo que caracteriza a estos dos personajes es precisamente que representan los dos ejemplos más claros de la habilidad del pueblo romano para conservar y reproducir los aprendizajes de la generación de Cannas. En este sentido, Moore argumenta que los mismos utilizan de forma consciente los ejemplos del pasado en el transcurso de sus carreras políticas, lo cual sirve, en parte, para explicar el éxito que corona sus acciones, pero además constituye una de las razones por las cuales el pueblo romano en su conjunto logra retrasar el inevitable ciclo de transformación constitucional. El episodio paradigmático es el de Escipión Emiliano tras el saqueo de Cartago, pues con sus palabras, este personaje representa, según Moore, la forma más elevada de aprendizaje de la obra de Polibio: el hombre político que reconoce y acepta el papel de la Fortuna en los asuntos humanos. En este sentido, la representación de su amigo cumple, según el autor, un papel fundamental, pues sirve como ejemplo del uso práctico que la lectura del género puede tener en la dirección de los asuntos públicos para aquellos que sean capaces de comprender los temas centrales de las Historias.

El análisis de la obra de Polibio que presenta Moore en este libro supone una lectura del texto que, en ocasiones, parece forzar la evidencia, como durante el análisis de los discursos de Aníbal y Escipión antes de Zama. Si bien es evidente que el propósito del general cartaginés se corresponde con sus conclusiones, no queda del todo claro que las 
palabras de Escipión reflejen los objetivos de sus hipótesis de trabajo. Asimismo, resulta difícil probar la conexión entre los resultados de los distintos capítulos porque, como señala el autor, a pesar de ser un autor prolífico en sus digresiones, muchas veces Polibio debe dejar que las conclusiones sean extraídas por el lector desde la narración misma de los hechos.

De cualquier modo, este libro es un aporte valioso para el estudio de las Historias. Interesará, por supuesto, especialmente a aquellos que deseen conocer más acerca de los aspectos metodológicos, pedagógicos e historiográficos, tan ricos y complejos, de la obra de Polibio, pero también será de utilidad para aquellos interesados por los aspectos narrativos e ideológicos del trabajo del historiador aqueo.

\section{Referencias bibliográficas}

Champion, C. (2004). Cultural Politics in Polybius' Histories. Berkeley: University of California Press.

Chaplin, J. (2001). Livy's Exemplary History. Oxford: Oxford University Press.

Moreno Leoni, Á. M. (2017). Entre Roma y el Mundo Griego. Memoria, autorrepresentación y didáctica del poder en las Historias de Polibio. Córdoba: Editorial Brujas.

Miltsios, N. (2013). The Shaping of Narrative in Polybius. Berlín: De Gruyter.

Ignacio Carral

Universidad de Buenos Aires ignaciocarral@gmail.com

Para citar esta reseña:

Carral, Ignacio (2021): Reseña bibliográfica, "Moore, D. W. (2020). Polybius. Experience and Lessons of History, Leiden - Boston: Brill, 168 pp." Anuario de la Escuela de Historia Virtual $19,168-171$. 